\title{
UNIFICAÇÃO DAS POLÍTICAS REGIONAIS DA SECRETARIA DE MEIO AMBIENTE: UMA PROPOSTA A PARTIR DA DIVISÃO POR BACIAS HIDROGRÁFICAS
}

\author{
Leandro Reginaldo Maximino Lelis ${ }^{1}$
}

RESUMO

Desde as décadas de 1960 e 1970, decretos e leis estabeleceram a política ambiental do Estado de São Paulo, determinando distintas divisões regionais. Destacam-se, entre elas, tendo como referência a noção de centralização e descentralização da gestão ambiental, a divisão do território paulista em 10 (dez) regionais vinculadas à fiscalização ambiental e à execução de projetos de preservação e recuperação ambiental e a divisão regional em 57 (cinquenta e sete) Agências Ambientais ligadas à CETESB, para atendimento das demandas de licenciamento. Considerando o antagonismo entre divisões regionais que integram o rol de atuação de uma mesma secretaria de governo, o presente trabalho discute a necessidade de revisão da política regional da Secretaria de Meio Ambiente (SMA). Nesse contexto, este trabalho tem como objetivo fortalecer a tese de que a adoção de uma divisão regional por bacias hidrográficas é a melhor opção para as políticas regionais da Secretaria de Meio Ambiente. A postura cientifica que adotamos para o desenvolvimento deste trabalho baseia-se em uma maneira comparativa e argumentativa a fim de que esta sustente e forneça embasamentos à nossa tese central. A unificação das políticas de regionalização da Secretaria de Meio Ambiente permitiria pesquisas e ações conjuntas entre os diferentes órgãos e esferas de governo, além de permitir a troca e a produção de dados unificados, que facilitaria a comparação e constatação dos avanços e regressos na área ambiental. Tal processo significaria otimização da gestão ambiental e atendimento aos preceitos do conceito de desenvolvimento sustentável.

PALAVRAS-CHAVE: Políticas regionais. Meio ambiente. Bacias hidrográficas.

\section{UNIFICATION OF REGIONAL POLICIES OF THE SECRETARY OF THE ENVIRONMENT: A PROPOSAL FROM THE DIVISION FOR WATERSHEDS}

\footnotetext{
${ }^{1}$ Mestrando no Programa de Pós-Graduação em Geografia da Universidade Federal de Mato Grosso do Sul, campus de Três Lagoas. Bolsista Fundect/Capes. E-mail: sukko51@hotmail.com.
} 


\begin{abstract}
Since the 1960s and 1970s, decrees and laws established the environmental policy of the State of São Paulo, determining distinct regional divisions. Stand out, among them, having as reference the notion of centralization and decentralization of environmental management, the division of the São Paulo territory within 10 (ten) regional linked to the regional environmental inspection and enforcement of preservation projects and environmental restoration and regional division by 57 (fifty-seven) Environmental Agencies linked to CETESB, to meet the demands of licensing. Considering the antagonism between regional divisions that integrate the list of actions of each secretariat of government, the present paper discusses the need for review of the Secretary of Environment (SMA) regional policy. In this context, this paper has the objective of strengthening the thesis that the adoption of a regional division by watersheds is the best option for the regional policies of the Secretary of Environment. The scientific posture we adopted to the development of this paper is based on a comparative and argumentative manner so that it sustain and provide emplacements to our central thesis. The unification of political regionalization of the Secretary of Environment would allow researches and joint actions among the different organs and spheres of government, besides allowing the exchange and the production of unified data, which facilitate comparison and verification of advances and regress in the environmental area. Such a process would mean optimization of environmental management and attendance with the precepts the concept of sustainable development.
\end{abstract}

KEYWORDS: Regional Policies. Environment. Watersheds.

\title{
UNIFICACIÓN DE LAS POLÍTICAS REGIONALES DEL DEPARTAMENTO DE MEDIO AMBIENTE: UNA PROPUESTA A PARTIR DE LA DIVISIÓN POR CUENCAS HIDROGRÁFICAS
}

\section{RESUMEN}

Desde los años 1960 y 1970, los decretos y las leyes establecidas política ambiental del Estado de São Paulo, determinando las divisiones regionales distintas. Destacan entre ellas con referencia a la noción de la centralización y la descentralización de la gestión ambiental, la división del territorio del Estado de São Paulo em 10(diez) regionales vinculados a la vigilancia ambiental regional y la ejecución de proyectos de conservación y restauración ambiental y la división regional en 57 (cincuenta y siete) Agencias Ambientales ligados a Cetesb para satisfacer las demandas de la concesión de licencias. Considerando que el antagonismo entre las divisiones regionales que integran la lista de acciones de cada entidad de gobierno, este trabajo discute la necesidad de una revisión de la política regional del Departamento de Medio Ambiente (SMA). En este contexto, el trabajo tiene como objetivo fortalecer la tesis de que la adopción de una división regional por las cuencas hidrográficas es la mejor opción para las políticas regionales del Departamento de Medio Ambiente. El enfoque científico que hemos adoptado para el desarrollo de este trabajo se 
basa en una forma comparativa y argumentativa para sostener esto y proporcionar justificación a nuestra tesis central. La unificación de las políticas de regionalización del Departamento de Medio Ambiente permitir la investigaciones y las acciones conjuntas entre los diferentes órganos y esferas de gobierno, además de permitir el intercambio y la producción de datos unificados, lo que facilita la comparación y verificación de los avances ambiental y regresos en el área ambiental. Tal proceso significaría optimización de la gestión ambiental y el cumplimiento de los preceptos del desarrollo sostenible.

PALABRAS-CLAVE: Políticas regionales. Medio ambiente. Cuencas hidrográficas.

\section{INTRODUÇÃO}

Durante décadas, desde os anos 1960/70, decretos e leis estabeleceram a política ambiental do Estado, determinando distintas divisões regionais. Destacamse, entre elas, tendo como referência a noção de centralização e descentralização da gestão ambiental, a divisão do território paulista em 10 (dez) regionais vinculadas à fiscalização ambiental e à execução de projetos de preservação e recuperação ambiental e a divisão regional em 57 (cinquenta e sete) Agências Ambientais ligadas à CETESB, para atendimento das demandas de licenciamento.

Considerando o antagonismo entre divisões regionais que integram o rol de atuação de uma mesma secretaria de governo, o presente trabalho discute a necessidade de revisão da política regional da Secretaria de Meio Ambiente (SMA). Nesse contexto, este trabalho tem como objetivo fortalecer a tese de que a adoção de uma divisão regional por bacias hidrográficas é a melhor opção para as políticas regionais da Secretaria de Meio Ambiente. Cabe salientar que a divisão por bacias hidrográficas já existe na administração pública desde o advento da Política Nacional de Recursos Hídricos, que definiu 22 (vinte e duas) Unidades de Gerenciamento de Recursos Hídricos (UGRHIS) no Estado de São Paulo.

Além da referida proposta, apresenta-se, no decorrer do trabalho, um breve histórico da política ambiental paulista e o referencial teórico que fundamenta as discussões sobre o conceito de região no âmbito geográfico.

A postura científica que adotamos para o desenvolvimento deste trabalho baseia-se em uma maneira comparativa e argumentativa a fim de que esta sustente e forneça embasamentos à nossa tese central. 
Primeiramente, realizamos uma pesquisa bibliográfica sobre a definição do conceito de região ao longo da evolução do pensamento geográfico. Em seguida, analisamos quais foram historicamente as políticas ambientais no Estado de São Paulo que desencadearam um processo de fundação de institutos e secretarias.

Na sequência, com o intuito de darmos continuidade ao modo comparativo de analisar os objetos, detalhamos quais são os tipos básicos de regionalização feita pelas políticas da SMA, que se configuraram em duas escalas, uma delas contendo 10 regiões e outra contendo 57 sub-regiões.

Por fim, investigamos quais foram as políticas de recursos hídricos do Estado de São Paulo e como se deu o desenvolvimento do comitê de bacias dessa Unidade da Federação, além de apontarmos o motivos que validam nossa tese.

\section{DESENVOLVIMENTO CONCEITUAL E TÉCNICO}

Antes de aprofundarmos nossa análise, temos a necessidade de realizar uma breve contextualização sobre o conceito de região no âmbito da Geografia.

$\mathrm{Na}$ Geografia Clássica, no final do século XIX, existiam duas correntes teóricas: o Determinismo alemão do espaço natural e das regiões naturais; e o Possibilismo francês focado no homem e na importância da abordagem regional.

No final do século XIX, no período de transição de métodos, surge a escola americana que trabalha com a diferenciação de áreas em que a região era uma mera abstração. Foi essa visão que possibilitou a expansão do quantitativismo da década de 1950. Matematizada, a Geografia Quantitativa propunha modelos de análises através de padrões.

Opositora da Geografia Quantitativa, a Geografia Crítica teve origem na França, na década de 1960, e se caracteriza por seu cunho marxista. É focada na produção do espaço e nas relações sociais. Nessa escola geográfica, a região era a escala intermediária entre o local e o global.

Junto à virada cultural linguística nas Ciências Sociais que ocorreu na década de 1970 nos Estados Unidos e na França, surge na Geografia a corrente teórica da 
Geografia Cultural, valorizando o espaço vivido, abstraído através das manifestações culturais, enfatizando a identificação territorial como forma de regionalização.

No que tange a definição de região de cunho mais pragmático queremos destacar o posicionamento de uma autora que traz algumas definições de região, onde constata a complexidade e variabilidade do conceito de região. Souza (1976) utiliza-se das proposições de Perroux e Boudevilli, que segundo ela é o ponto de partida de vários estudos no campo do planejamento e da ciência regional, onde alguns de seus conceitos são: a região homogênea; a região polarizada; e, a região operacional. Aqui temos um divisor importante, haja vista que as políticas atuais de regionalização quanto à questão ambiental e a questão hidrográfica no Estado de São Paulo, estão estritamente relacionadas aos preceitos de região operacional. $O$ que queremos desenvolver neste trabalho é uma forma de regionalização homogênea, integrando as esferas legislativa, técnica e institucional, as políticas da SMA e o comitê de bacias hidrográficas.

Assim, optamos pelo posicionamento de Souza (1976), em que a região é uma unidade do planejamento territorial e o planejamento deve priorizar o autoconhecimento da região. O autoconhecimento é necessário para que se leve em conta as especificidades regionais durante o processo de planejamento. Esse posicionamento é vital para sustentarmos nossa ideia de regionalização sob a ótica da divisão regional por meio de bacias hidrográficas.

\subsection{Sob o âmbito da lei}

No ano de 1973 foi autorizado, por meio da publicação da Lei Estadual $n^{\circ}$ 118/1973, a criação da Companhia Estadual de Tecnologia de Saneamento Básico (CETESB), configurada como empresa mista de capital público e privado. Originalmente, conforme 0 artigo $1^{\circ}$ da referida Lei, a companhia tratava basicamente do controle da poluição das águas.

No ano de 1976, o Governo do Estado de São Paulo editou a Lei n 997/1976, que dispõe sobre o controle da poluição do meio ambiente. O advento desta norma, 
conforme seus artigos $1^{\circ}$ e $2^{\circ}$, formalizou a noção de sistema de prevenção e controle da poluição da água, solo ou ar, ocasionada pelo lançamento ou liberação de qualquer forma de matéria ou energia com quantidade ou intensidade em desacordo com o estabelecido por ela. Outra inovação abarcada no artigo $5^{\circ}$ da mesma lei diz respeito à necessidade de autorização prévia do órgão estadual de controle da poluição do meio ambiente, mediante licenças de instalação e funcionamento. No seu artigo $7^{\circ}$, definiu penalidades a infratores e a interdição ou embargo das atividades lesivas ou não autorizadas.

Ainda em 1976, no mês de maio, o texto da Lei de Prevenção e Controle da Poluição do Meio Ambiente foi aprovado e regulamentado pelo Decreto Estadual $n^{\circ}$ 8.468/1976, que estabeleceu os padrões de qualidade ambiental do ar, da água e do solo e conferiu à CETESB, em quinze incisos ${ }^{2}$ integrantes do artigo $6^{\circ}$, suas atribuições destinadas ao controle e preservação do meio ambiente.

Em âmbito federal, somente em 1981 foram estabelecidos os objetivos e instrumentos da Política Nacional de Meio Ambiente, editados pela Lei $n^{\circ}$ 6.938/1981. Esta Lei permitiu, pela primeira vez no país, conceber a conciliação entre desenvolvimento econômico com preservação ambiental e qualidade de vida. A rederida Lei também criou: o Instituto Brasileiro do Meio Ambiente e dos Recursos Naturais Renováveis (IBAMA), órgão licenciador e fiscalizador de matérias atinentes às questões ambientais a serem tratadas pela União; o Sistema Nacional de Meio

\footnotetext{
${ }^{2}$ I - estabelecer e executar planos e programas de atividades de prevenção e controle da poluição; II efetuar levantamentos, organizar e manter o cadastramento de fontes de poluição; III - programar e realizar coleta de amostras, exames de laboratórios e análises de resultados, necessários à avaliação da qualidade do referido meio; IV - elaborar normas especificações e instruções técnicas relativas ao controle da poluição; $\mathrm{V}$ - avaliar o desempenho de equipamentos e processos, destinados aos fins deste artigo; VI - autorizar a instalação, construção, ampliação, bem como a operação ou funcionamento das fontes de poluição definidas neste regulamento; VII - estudar e propor aos Municípios, em colaboração com os órgãos competentes do Estado as normas a serem observadas ou introduzidas nos Planos Diretores urbanos e regionais do interesse do controle da poluição e da preservação do mencionado meio; VIII - fiscalizar as emissões de poluentes feitas por entidades públicas e particulares; IX - efetuar inspeções em estabelecimentos, instalações e sistemas que causem ou possam causar a emissão de poluentes; $X$ - efetuar exames em águas receptoras, efluentes e resíduos; XI - solicitar a colaboração de outras entidades, públicas ou particulares, para a obtenção de informações sobre ocorrências relativas à poluição do referido meio; XII - fixar, quando for o caso, condições a serem observadas pelos efluentes a serem lançados nas redes de esgotos; XIII - exercer a fiscalização e aplicar as penalidades previstas neste regulamento; XIV - quantificar as cargas poluidoras e fixar os limites das cargas permissíveis por fontes, nos casos de vários e diferentes lançamentos e emissões em um mesmo corpo receptor ou em uma mesma região; XV analisar e aprovar planos e programas de tratamento e disposição de esgotos.
} 
Ambiente (SISNAMA), formado por um órgão colegiado; e, o Conselho Nacional do Meio Ambiente (CONAMA), cuja composição congrega representantes de ministérios e entidades setoriais da administração federal diretamente relacionados à questão ambiental, além de órgãos ambientais estaduais e municipais, entidades de classe e ONGs.

Em São Paulo, o governo ampliou a abrangência e a complexidade das normas ambientais a partir de 1986, transformando, por meio do Decreto Estadual $\mathrm{n}^{\circ}$ 24.715/1986, a Divisão de Proteção dos Recursos Naturais, vinculada até então à Secretaria de Agricultura e Abastecimento, em Departamento Estadual de Proteção de Recursos Naturais (DPERN).

Em 1986, por meio do Decreto Estadual n 24.932/1986, o Governo de São Paulo institui o Sistema Estadual do Meio Ambiente e criou a Secretaria de Estado do Meio Ambiente, que assumiram a responsabilidades pela execução de programas e projetos na área de defesa, preservação e melhoria do meio ambiente e de controle e fiscalização de atividades que degradam a qualidade ambiental.

No ano de 1989, houve nova reformulação na política estadual de meio ambiente. O Decreto $n^{\circ} 30.555 / 1989$ reorganizou a Secretaria de Meio Ambiente, transformando-a no órgão seccional paulista do Sistema Nacional do Meio Ambiente. Dessa forma, assumiu, conforme o artigo $2^{\circ}$ do Decreto, a posição de órgão central do Sistema Estadual do Meio Ambiente (SISEMA), assumindo sua coordenação. Destaque-se o inciso XVI do referido artigo, que atribui à SMA a responsabilidade pelo licenciamento das atividades efetivas ou potencialmente poluidoras. Nessa estrutura, o DEPRN foi transformado em Coordenadoria de Proteção de Recursos Naturais (CPRN), subordinada à SMA e responsável direta pela concessão das licenças ambientais no Estado.

Após inúmeras alterações de denominação dos órgãos, mantendo-se baixo grau de descentralização, a Lei Estadual n 13.542/2009 conferiu nova denominação à CETESB, além de lhe conferir novas atribuições, conforme os incisos do artigo $2^{\circ}$ da $\operatorname{Lei}^{3}$.

\footnotetext{
${ }^{3} \mathrm{I}$ - proceder ao licenciamento ambiental de estabelecimentos e atividades utilizadoras de recursos ambientais, considerados efetiva e potencialmente poluidores, bem como capazes, sob qualquer forma, de causar degradação ambiental; II - autorizar a supressão de vegetação e intervenções em
} 
Recentemente, o Decreto Estadual n 57.933/2012 reorganizou a Secretaria de Meio Ambiente, que atualmente é composta pelo Conselho Estadual do Meio Ambiente (CONSEMA), por cinco coordenadorias (Coordenadoria de Biodiversidade e Recursos Naturais/CBRN; Coordenadoria de Educação Ambiental/CEA; Coordenadoria de Planejamento Ambiental/CPLA; Coordenadoria de Fiscalização Ambiental/CFA; Coordenadoria de Parques Urbanos/CPU), pelos Institutos de Botânica (IBt), Florestal (IF) e Geológico (IG), além de entidades vinculadas: Fundação para a Conservação e a Produção Florestal do Estado de São Paulo, Fundação Parque Zoológico de São Paulo e Companhia Ambiental do Estado de São Paulo (CETESB).

\subsection{Política regional da Secretaria de Meio Ambiente}

Ao longo de todo o período de desenrolar dos decretos e leis que estabeleceram a política ambiental do Estado de São Paulo, foram determinadas distintas divisões regionais ligadas à política ambiental no território paulista. Destacam-se, em situações opostas em termos de centralização e descentralização da gestão ambiental:

a) Divisão em 10 (dez) regionais vinculadas à fiscalização ambiental e à execução de projetos de preservação e recuperação ambiental (Figura 1). Nessa divisão, existe um Centro Técnico Regional (CTR) para cada região. Nota-se relativa descentralização das políticas públicas ambientais, em desacordo com o que preconiza a Política Nacional do Meio Ambiente (Lei $n^{\circ}$ 6.938/1981) ao permitir e incentivar os estados e municípios quanto à elaboração de suas próprias normas de gestão. Em sentido oposto, a atuação centralizada dificulta o acesso aos órgãos ambientais, tanto para atendimento às demandas de fiscalização dos próprios órgãos quanto em relação às necessidades de licenciamento e enfrentamento da

áreas consideradas de Preservação Permanente e demais áreas ambientalmente protegidas; III emitir alvarás e licenças relativas ao uso e ocupação do solo em áreas de proteção de mananciais; IV - emitir licenças de localização relativas ao zoneamento industrial metropolitano; $V$ - fiscalizar e impor penalidades. 
burocracia governamental pelos usuários de recursos naturais ou empreendedores que dependem de autorização para suas atividades.

Figura 1 - Regiões de abrangência dos Centros Técnicos Regionais

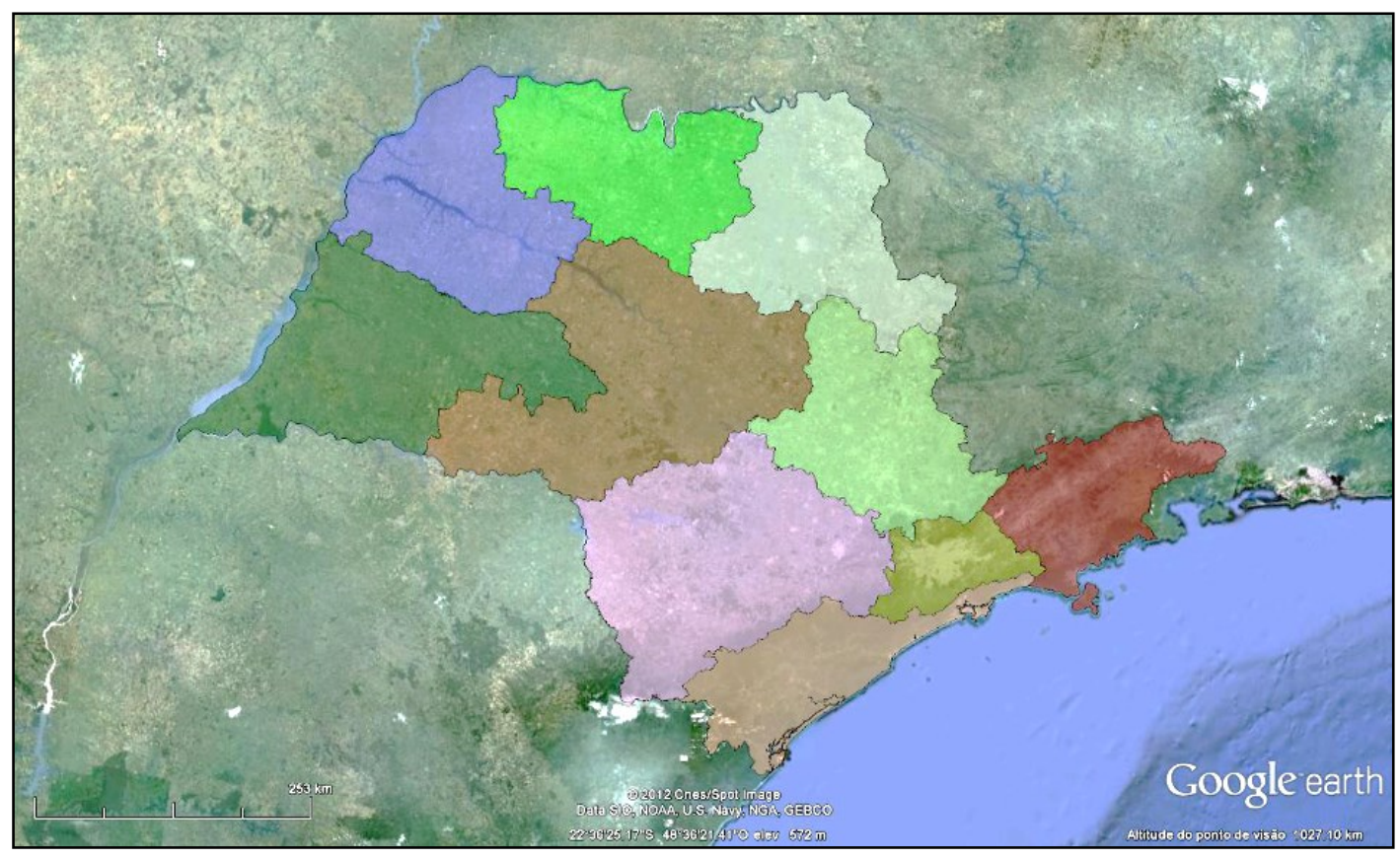

2014.
Fonte: Google Earth,

b) Divisão regional em 57 (cinquenta e sete) Agências Ambientais (Figura 2) ligadas à CETESB, para atendimento das demandas de licenciamento, ou seja, obtenção de autorizações para supressão de vegetação, instalação de obras e empreendimentos e demais intervenções que requeiram processo de licenciamento. Institucionalmente, a CETESB está subordinada à SMA. No entanto, o fato de tratarse de empresa de capital misto, com ações negociadas na bolsa de valores e importantes investidores privados, a companhia goza de atenção especial do governo quanto à injeção de recursos e condições de trabalho de seu corpo técnico.

Figura 2 - Regiões de abrangência das Agências Ambientais 


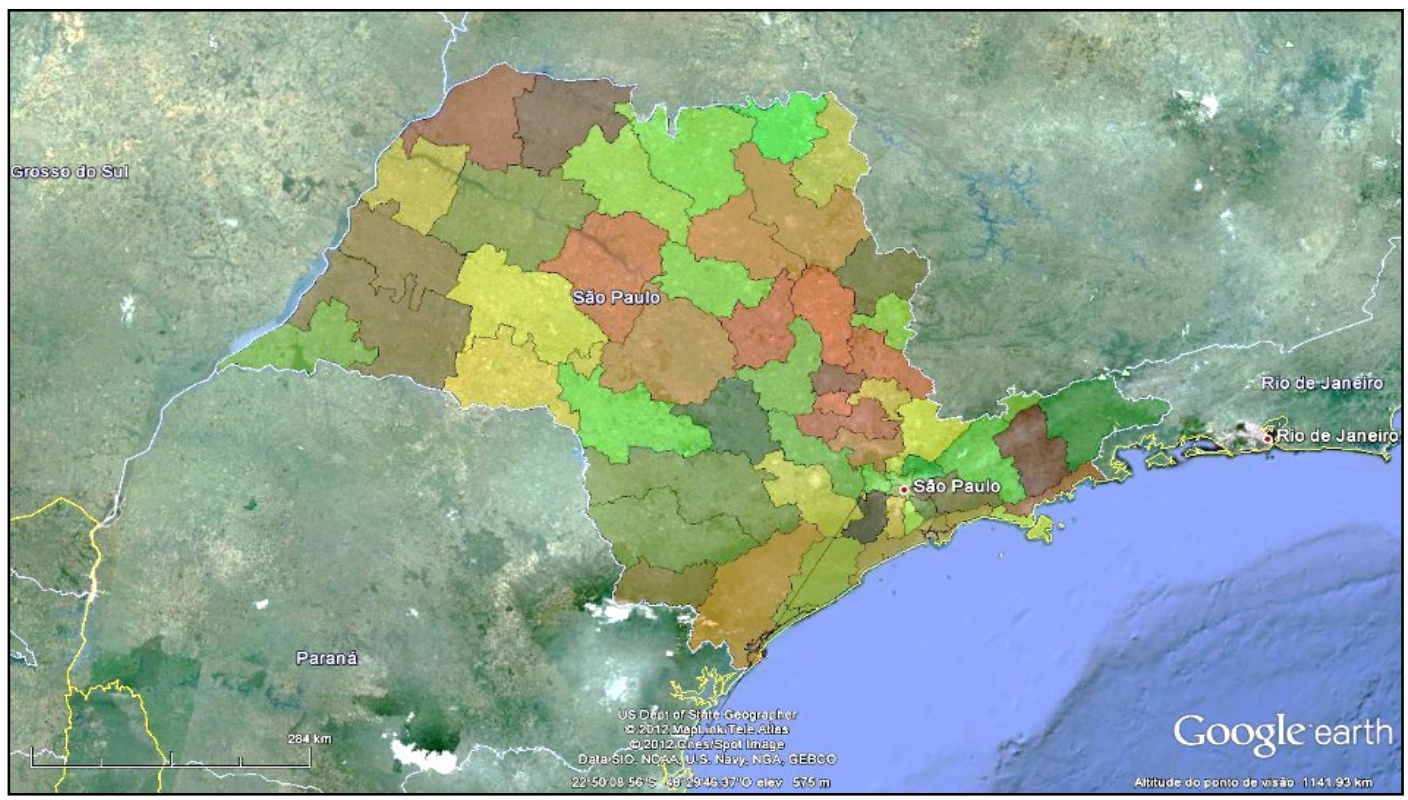

Fonte: Google Earth, 2014

Ainda que existam problemas quanto ao número reduzido de estações de monitoramento de qualidade da água nos rios estaduais ou de fiscalização sobre poluidores, por exemplo, a CETESB atua em condições privilegiadas de funcionamento em comparação ao que ocorre nas coordenadorias com vinculação direta à Secretaria de Meio Ambiente. Quanto à política regional, a CETESB atua de forma mais descentralizada que os demais órgãos do Sistema Estadual do Meio Ambiente.

\subsection{Política de recursos hídricos do Estado de São Paulo}

A conservação dos recursos naturais e o seu uso consciente e sustentável é cada vez mais pauta de discussões políticas e ambientais por todo o mundo. Um dos principais recursos naturais que se deseja conservar pela sua importância singular para a vida no planeta é a água, que teve seu uso indiscriminado ao longo da história, pela falsa noção de abundância e infinidade, que atualmente alarma à futura escassez.

A discussão política acerca da gestão e controle destes recursos é extremamente importante para que haja a garantia legal do uso consciente e 
sustentável dos mesmos, garantindo a qualidade ambiental e de vida. Assim, a Constituição Federal promulgada em 1988 caminha no sentido de uma gestão descentralizada e participativa dos recursos hídricos, com vários atores políticos envolvidos.

A Constituição do Estado de São Paulo, promulgada no ano seguinte, propõe um "Sistema de Gerenciamento dos Recursos Hídricos", que tem o objetivo de instituir um novo conceito de que a água é um bem público, dotado de valor econômico e que tem sua importância ambiental, negando a antiga postura de exploração indiscriminada. Sua proposta da gestão também segue a lógica descentralizadora, de forma participativa e integrada em relação às peculiaridades das bacias hidrográficas.

Segundo a Secretaria de Energia, Recursos Hídricos e Saneamento do Estado de São Paulo é a partir da Lei Estadual $n^{\circ} 7663$, promulgada em 1991, que se instituiu a Política de Recursos Hídricos. A Lei Estadual n 9.034, do ano de 1994, aprovou o Plano Estadual de Recursos Hídricos e propôs a divisão do Estado de São Paulo em 22 Unidades de Gerenciamento de Recursos Hídricos - UGRHI, havendo também 21 Comitês de Bacias Hidrográficas (CBH).

Silva e Pinto (2013) apontam que a utilização da bacia hidrográfica como unidade de análise, planejamento e gerenciamento dos recursos hídricos

[...] originou-se da percepção de que os ecossistemas são essencialmente abertos, trocam energia e matéria entre si, com os ecossistemas terrestres adjacentes, sofrem alterações de diferentes tipos em virtudes do uso do solo e das atividades antropogênicas nele desenvolvidas (SILVA; PINTO, 2013, p. 2).

Apesar da importância do ciclo da água para os ecossistemas dentro de uma bacia, as atividades humanas cada vez mais interferem neste ciclo. Tal situação provoca mudanças significativas neste ciclo, implicando no risco de uma futura escassez de água, seja em função da falta de água em quantidade ou em qualidade (SILVA et al, 2011).

Segundo Silva et al (2011), para que as interferências humanas no ciclo da água sejam minimizadas, sem que o abastecimento necessário às atividades 
produtivas seja afetado, é necessário "[...] que sejam estabelecidos sistemas de gestão integrados, que considerem as características do ciclo natural das águas e dos ecossistemas e o conjunto das necessidades humanas" (SILVA et al, 2011, p. 13).

Dessa forma, para Silva et al (2011, p. 13): “[...] a gestão das águas por bacias hidrográficas é a melhor opção, uma vez que esta unidade de gestão é definida pela própria natureza ao longo de sua história evolutiva”. Ainda de acordo com os autores, para que o gerenciamento dos recursos hídricos de uma bacia seja realizado da maneira adequada

[...] é preciso considerar os aspectos físicos de relacionamento entre a terra e a água, superficial e subterrânea, o manejo destas águas pelas pessoas que delas utilizam e as relações econômicas oriundas da utilização da mesma água no sistema bacia, tais como irrigação, geração de energia e dessedentação de pessoas e criações (SILVA et al, 2011, p. 14).

Com o Sistema Integrado de Gerenciamento de Recursos Hídricos (SIGRH) e a Política Estadual de Recursos Hídricos (PERH) o Estado de São Paulo passou a ser exemplo de gestão, haja vista que essas políticas possuem a proposta de gestão participativa que envolve além dos agentes políticos oficiais, os cidadãos e produtores, que são os maiores e efetivos usuários destes recursos.

Assim, preza-se pela participação e integração dos atores políticos e sociais locais voltados ao uso dos recursos visando à promoção do desenvolvimento econômico sustentável, com produção eficiente, que não desperdice e nem polua a água.

Dessa forma, a melhor opção é a gestão estratégica pelos Comitês de Bacias, que ao fazer estudos que identificam problemas ambientais em áreas específicas da bacia podem organizar ações mais efetivas visando reverter os problemas diagnosticados, permitindo também traçar diretrizes para os projetos desenvolvidos.

Ressaltando os aspectos positivos destas políticas, Azevedo et al (2007) afirmam que:

A indicação de ações prioritárias pelo Comitê, como a elaboração de projetos para o planejamento e gerenciamento estratégico e a implementação de programas permanentes de Educação Ambiental para os recursos hídricos, vêm contribuindo para que os administradores públicos 
mudem sua postura político-administrativa com as questões relativas a água, muitas vezes norteando e exigindo ações que garantam qualidade de vida. Nestes mais de 15 anos da Política Estadual de Recursos Hídricos (São Paulo), nota-se uma melhoria considerável do quadro sócioeconômico-ambiental das Bacias Hidrográficas em todo território Paulista (AZEVEDO et al, 2007, p. 5-6).

Diante da necessidade de descentralizar a gestão ambiental, de tal forma que os atores locais estejam efetivamente inseridos no processo decisório e de maneira que haja maior eficiência na atuação do Estado na fiscalização e execução das medidas legais destinadas à conservação e à proteção ambiental, propõe-se a adoção integrada da divisão regional por bacias hidrográficas para gestão (Figura 3).

Figura 3 - Unidades de Gerenciamento de Recursos Hídricos (22 UGRHIs).

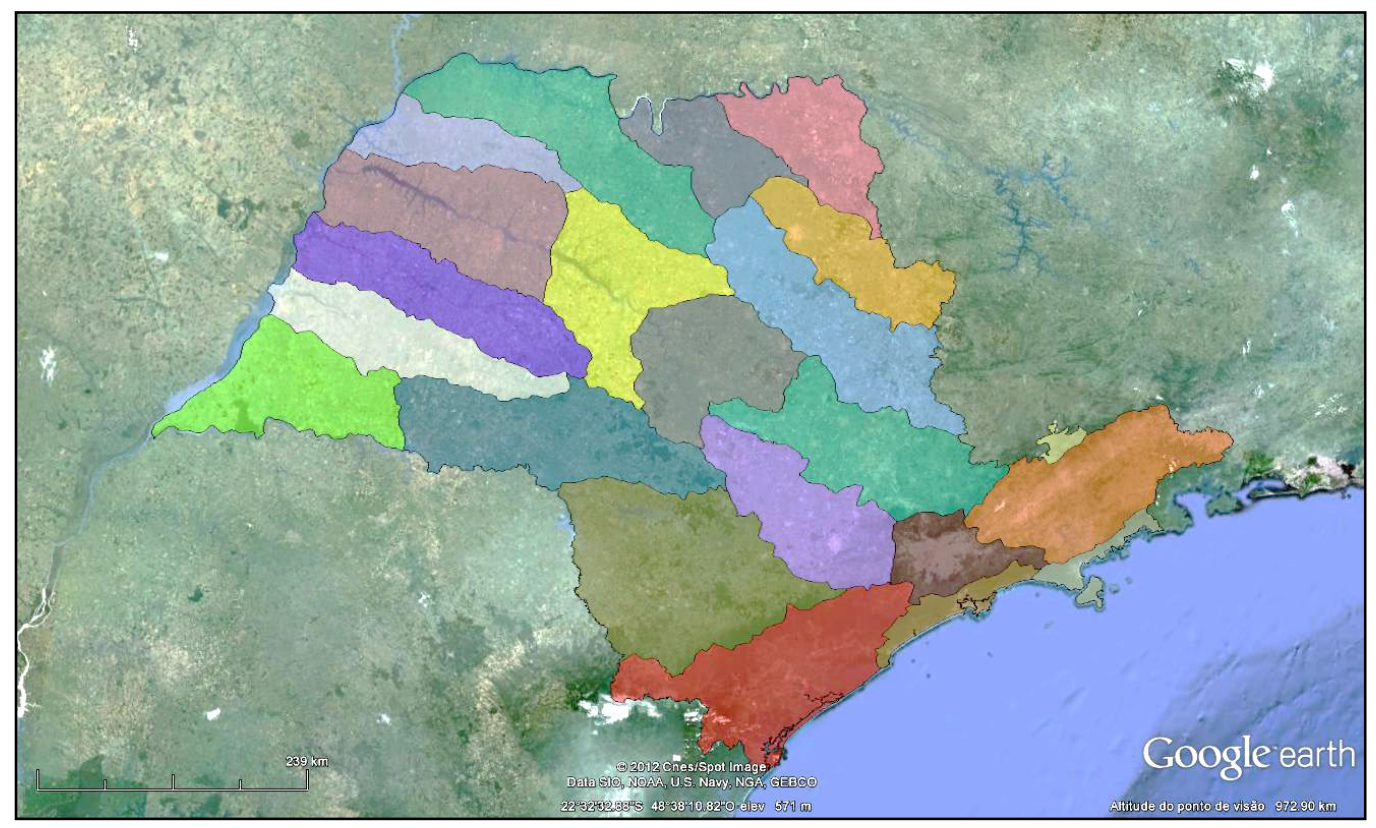

Fonte: Google Earth, 2014

Assim, nossa proposta gravita em torno da adoção de uma regionalização unificada dentro da área ambiental e da administração pública, promovendo maior facilidade na integração tanto das políticas quanto do desenvolvimento técnico e científico acerca do tema. 


\section{CONCLUSÃO}

A unificação das políticas de regionalização da Secretaria de Meio Ambiente permitiria pesquisas e ações conjuntas entre os diferentes órgãos e esferas de governo, além de permitir a troca e a produção de dados unificada. Isso facilitaria a comparação e a constatação dos avanços e regressos na área ambiental. Dessa forma, as especificidades climáticas, geomorfológicas e biológicas regionais seriam, possivelmente, respeitadas. Tal processo significaria otimização da gestão ambiental e atendimento aos preceitos do conceito de desenvolvimento sustentável em que pese de igual importância as dimensões ambiental, social e econômica, não sendo esta última impositiva de critérios e padrões em detrimento da garantia de acesso, pelas gerações atuais e futuras, a um ambiente saudável e ecologicamente equilibrado.

Destarte, é possível, mediante investimentos em estruturas regionais adequadas, adotar a divisão por unidades de gerenciamento que considere os limites das bacias hidrográficas para a definição da política regional da Secretaria de Meio Ambiente do Estado de São Paulo. Resta à população e aos grupos políticos interessados aprofundar os debates sobre a temática para que tal necessidade não seja escamoteada.

\section{REFERÊNCIAS}

AZEVEDO, F. Z; MODAELLI, S. D. O; RANZANI, A. J. T; SABBAG, E. G. Gestão dos recursos hídricos no Estado de São Paulo. I Simpósio de Recursos Hídricos do Norte e Centro-Oeste, Cuiabá - MT, 2007. Disponível em

<http://www.abrh.org.br/novo/i_simp_rec_hidric_norte_centro_oeste86.pdf>. Acesso em: 15 abr. 2014. p 1-6.

BRASIL. Lei $n^{\circ}$ 6.938, de 31 de agosto de 1981. Dispõe sobre a Política Nacional do Meio Ambiente, seus fins e mecanismos de formulação e aplicação, e dá outras providências. Poder Legislativo, Senado, Brasília, 1981.

CASTRO, I. E; GOMES, P.C.C; CORRÊA, R.L. Explorações Geográficas. Rio de Janeiro: Bertrand Brasil, 1997.

CORREAA, R. L. Diferenciação sócio-espacial, escala e práticas espaciais. In: CIDADE. N. 06, Vol. 04, p 61-72, 2007.

CETESB. Companhia de Tecnologia de Saneamento Ambiental. Agências Ambientais. Disponível em: <http://www.cetesb.sp.gov.br>. Acesso em: 10 fev. 2014. 
DAEE. Departamento de Águas e Energia Elétrica. Unidades de Gerenciamento de Recursos Hídricos - UGRHIS, 2003. Disponível em: <http://www.daee.sp.gov.br>. Acesso em: 5 mar. 2012.

Departamento de Águas e Energia Elétrica. 1984. Caracterização dos recursos hídricos no Estado de São Paulo. São Paulo. DAEE, 175p.

HAESBAERT, R. Territórios alternativos. Niterói: Ed. UFF; São Paulo: Contexto, 2002.

LENCIONI, S. Perspectivas contemporâneas da Geografia Regional. Região e Geografia. São Paulo: Edusp. 1999.

MOREIRA, R. Da região à rede e ao lugar: a nova realidade e o novo olhar sobre o mundo. Etc..., espaço, tempo e crítica. n. 1 (3), Rio de Janeiro, 2007.

SÃO PAULO. Lei no 118, de 29 de junho de 1973. Autoriza a constituição de uma sociedade por ações, sob a denominação de CETESB - Companhia Estadual de Tecnologia de Saneamento Básico e de Controle de Poluição das Águas, e dá providências correlatas. Imprensa Oficial do Estado [DOE], 29 de junho de 1973. São Paulo, SP.

Lei $n^{\circ}$ 997, de 31 de maio de 1976. Dispõe sobre o controle da poluição do meio ambiente. Imprensa Oficial do Estado [DOE], 31 de maio de 1973. São Paulo, SP.

Decreto $n^{\circ} 8.468$, de 8 de setembro de 1976. Aprova o Regulamento da Lei ${ }^{\circ} 997$, de 31 de maio de 1976, que dispõe sobre a Prevenção e o Controle da Poluição do Meio Ambiente. Imprensa Oficial do Estado [DOE], 8 de setembro de 1976. São Paulo, SP.

Decreto $\mathrm{n}^{\circ} 24.715$, de 7 de fevereiro de 1986. Transforma a Divisão de Proteção de Recursos Naturais, da Coordenadoria da Pesquisa de Recursos Naturais, da Secretaria de Agricultura e Abastecimento, em Departamento Estadual de Proteção de Recursos Naturais, dispõe sobre sua organização e dá providências correlatas. Imprensa Oficial do Estado [DOE], 7 de fevereiro de 1976. São Paulo, SP.

Decreto Estadual n 24.932/1986, de 24 de março de 1986. Institui o Sistema Estadual do Meio Ambiente, cria a Secretaria de Estado do Meio Ambiente, e dá providências correlatas. Imprensa Oficial do Estado [DOE], 24 de março de 1986. São Paulo, SP.

Decreto $n^{\circ} 30.555 / 1989$, de 3 de outubro de 1989. Reestrutura, reorganiza e regulamenta a Secretaria do Meio Ambiente e dá providências correlatas. Imprensa Oficial do Estado [DOE], 3 de outubro de 1989. São Paulo, SP.

Lei Estadual no 13.542, de 8 de maio de 2009. Altera a denominação da CETESB Companhia de Tecnologia de Saneamento Ambiental e dá nova redação aos artigos $2^{\circ}$ e 10 da Lei $n^{\circ}$ 118, de 29 de junho de 1973. Imprensa Oficial do Estado [DOE], 8 de maio de 2009. São Paulo, SP.

Decreto $n^{\circ}$ 57.933/2012, de 2 de abril de 2012. Reorganiza a Secretaria do Meio Ambiente e dá providências correlatas. Imprensa Oficial do Estado [DOE], 2 de abril de 2012. São Paulo, SP.

SILVA, P. V.; PINTO, A. L.; CARVALHO, E. M.; PIROLI, E. L. A visão sistêmica na gestão de bacias hidrográficas. Anais XIX Simpósio Brasileiro de Recursos Hídricos. Associação Brasileira de Recursos Hídricos - ABRH. Maceió, 2011. p. 1-15.

SILVA, C. A. A.; PINTO, A. L. Qualidade das águas superficiais do Rio Sucuriú, no município de Três Lagoas/MS. 2013. p. 1-19. Disponível em:

<http://www.propp.ufms.br/gestor/titan.php?target=openFile\&fileld=407>. Acesso em: 13 dez. 2013. 
SMA. Secretaria de Estado do Meio Ambiente de São Paulo. Centros Técnicos Regionais. Disponível em: <http://www.ambiente.sp.gov.br>. Acesso em 05 de meio de 2014.

SOUZA, M. A. Regionalização: tema geográfico e político - o caso paulista. In: Boletim Paulista de Geografia. n. 50, AGB, p. 103-141, 1976.

SRH - Secretaria de Energia, Recursos Hídricos e Saneamento do Estado de São Paulo. 1998. Caracterização das unidades de gerenciamento de recursos hídricos. 52p.

THAME, A. C. M. (org.). Comitê de Bacias Hidrográficas: uma revolução conceitual. São Paulo/SP: Iqual, 2002. 